OPEN ACCESS

Edited by:

Jianguang Ji,

Lund University, Sweden

Reviewed by:

Chi-kong Li,

The Chinese University of Hong Kong,

China

Volkert Siersma

University of Copenhagen, Denmark

*Correspondence:

Friederike Erdmann

friederike.erdmann@uni-mainz.de

${ }^{\dagger}$ These authors have contributed equally to this work and share second authorship

Specialty section:

This article was submitted to Cancer Epidemiology and Prevention, a section of the journal Frontiers in Oncology

Received: 17 August 2021 Accepted: 26 October 2021 Published: 26 November 2021

Citation:

Erdmann F, Frederiksen LE, Mogensen H, Pedersen C, Mader L, Talbäck M, Bautz A, Hirvonen E, Kyrönlahti A, Korhonen LM, Hasle H,

Malila N, Madanat-Harjuoja L-M, Feychting M and Winther JF (2021) Cohort Profile: The Socioeconomic Consequences in Adult Life After Childhood Cancer in Scandinavia (SALiCCS) Research Programme.

Front. Oncol. 11:752948. doi: 10.3389/fonc.2021.752948

\section{Cohort Profile: The Socioeconomic Consequences in Adult Life After Childhood Cancer in Scandinavia (SALiCCS) Research Programme}

Friederike Erdmann ${ }^{1,2 *}$, Line Elmerdahl Frederiksen ${ }^{1 \dagger}$, Hanna Mogensen ${ }^{3 \dagger}$, Camilla Pedersen ${ }^{1}$, Luzius Mader ${ }^{1,4}$, Mats Talbäck ${ }^{3}$, Andrea Bautz ${ }^{1}$, Elli Hirvonen ${ }^{5}$, Anniina Kyrönlahti ${ }^{5,6}$, Liisa Maria Korhonen ${ }^{5,6}$, Henrik Hasle ${ }^{7}$, Nea Malila ${ }^{5}$, Laura-Maria Madanat-Harjuoja ${ }^{5,8}$, Maria Feychting $^{3}$ and Jeanette Falck Winther ${ }^{1,9}$

${ }^{1}$ Childhood Cancer Research Group, Danish Cancer Society Research Center, Copenhagen, Denmark, 2 Division of Childhood Cancer Epidemiology, Institute of Medical Biostatistics, Epidemiology and Informatics (IMBEI), Johannes Gutenberg University Mainz, Mainz, Germany, ${ }^{3}$ Unit of Epidemiology, Institute of Environmental Medicine, Karolinska Institutet, Stockholm, Sweden, ${ }^{4}$ Institute of Social and Preventive Medicine (ISPM), University of Bern, Bern, Switzerland, ${ }^{5}$ Institute for Statistical and Epidemiological Cancer Research, Finnish Cancer Registry, Helsinki, Finland, 6 New Children's Hospital, University of Helsinki and Helsinki University Hospital, Helsinki, Finland, 7 Department of Paediatrics, Aarhus University Hospital, Aarhus, Denmark, ${ }^{8}$ Dana Farber Cancer Institute/Boston Children's Cancer and Blood Disorders Center, Harvard Medical School, Boston, MA, United States, ${ }^{9}$ Department of Clinical Medicine, Faculty of Health, Aarhus University and Aarhus University Hospital, Aarhus, Denmark

Introduction: The growing number of survivors of childhood cancer, with many years of life ahead, demonstrates the increasing clinical and public health relevance of investigating the risks of social and socioeconomic impairment after a childhood cancer diagnosis and the life-saving treatment. To enrich understanding of the mental, social and socioeconomic difficulties that childhood cancer survivors may face during their lifecourse, identify particularly vulnerable survivors and overcome the limitations of previous research, we initiated the Socioeconomic Consequences in Adult Life after Childhood Cancer in Scandinavia (SALiCCS) research programme.

Methods: This Nordic cross-border research programme is a collaboration between the Danish Cancer Society, the Finnish Cancer Registry and Karolinska Institutet to investigate a broad range of mental, social and socioeconomic conditions in long-term childhood cancer survivors in Denmark, Finland and Sweden. SALiCCS is based on a registry-based matched cohort design, comprising five-year survivors of cancer diagnosed at ages 0-19 years (1971-2008 in Denmark, 1971-2009 in Finland, 1971-2011 in Sweden), age-, sexand country-matched population comparisons and sibling comparisons who were followed over time. Outcomes of interest included mental disorders, educational achievements, employment and profession, family life and the need of social security benefits. Individual-level data linkage among various national registries provided the data for the research programme.

Results: The SALiCCS core population comprises 21,292 five-year survivors, 103,303 population comparisons and 29,644 siblings as a second comparison group. The most 
common diagnoses in survivors were central nervous system tumours, leukaemias and lymphomas.

Discussion: SALICCS is the largest, most comprehensive population-based research initiative in this field, based on high-quality registry data with minimal risk of bias. The findings will be informative for evidence-based survivorship care targeting not only somatic late effects but also psychosocial impairments.

Keywords: childhood cancer survivors, survivorship, social and socioeconomic outcomes, family life, registerbased research, Denmark, Finland, Sweden

\section{INTRODUCTION}

Childhood cancer is of increasing public health concern, as approximately 35,000 new cases are diagnosed yearly in children and adolescents in Europe, and about 500,000 European Union citizens are childhood cancer survivors, with complex needs for medical and psycho-social care (1). Although a growing body of research has addressed a broad range of potential risk factors, the aetiology of most childhood cancers is still largely unknown $(2,3)$. With remarkable advances in diagnostics and treatment $(4,5)$, the five-year survival after childhood cancer has improved from $30 \%$ in the 1960 s to more than $80 \%$ nowadays in most of Europe (6-8). As a result of the increasing survival and lack of primary preventive measures $(2,3,9)$, the number of childhood cancer survivors in society is growing steadily. This growing population is at risk of long-term health consequences (i.e. late effects) induced by the cancer or the intensive treatment at a young age $(8,10-12)$. Although many survivors are well after therapy, a wide spectrum of long-term adverse health consequences in childhood cancer survivors has been described $(8,12-18)$, indicating higher risks of a broad range of somatic and mental late effects, including second cancers ( 8 , $12,17,18)$, higher overall mortality rates $(12,16)$, severe chronic health conditions $(8,12-15)$, mental disorders (19, 20 ) and use of antidepressants (21).

The experience of cancer during childhood and adverse somatic or mental health conditions may also have consequences for social and family life and for socioeconomic achievement later in life. Previous research has shown that childhood cancer survivors are at increased risk of several adverse socioeconomic and social outcomes, including scholastic difficulties, such as requiring special education or attending learning disability programmes, lower levels of attained education and lower income than their peers (22). There are only few studies on the uptake of social security benefits in survivors, and almost all are from the Nordic countries. Increased uptake of various social security benefits by survivors was reported consistently (22). Empirical

\footnotetext{
Abbreviations: ALiCCS, Adult Life after Childhood Cancer in Scandinavia; CNS, Central Nervous System; NOPHO, Nordic Society of Paediatric Haematology and Oncology; SALiCCS, Socioeconomic Consequences in Adult Life after Childhood Cancer in Scandinavia.
}

observations on employment and occupation are less conclusive $(22,23)$, with heterogeneous findings from Europe $(22,23)$ and a consistently higher risk of unemployment among survivors in studies from Canada and the USA (23-25).

The current evidence is limited by methodological shortcomings. Most previous research is based on self-reported information from surveys and are thereby susceptible to nonparticipation, which might have affected the outcomes. Further, many studies included survivors of only one or a few specific childhood cancer types, did not involve repeated measurements of social and socioeconomic outcomes throughout the life-course or suffered from substantial loss to follow-up. Further limitations of previous studies include insufficient sample size of survivors and short follow-up. The mechanisms that lead to adverse social and socioeconomic conditions, especially in vulnerable subgroups of survivors, are still poorly understood $(22,26)$, and better knowledge would be of significant importance for developing interventions and supportive strategies for these vulnerable groups.

The Socioeconomic Consequences in Adult Life after Childhood Cancer in Scandinavia (SALiCCS) research programme was initiated to address these gaps and enrich understanding of the impairments and social and socioeconomic difficulties that survivors of childhood cancer may face during their life-course. This Nordic research programme is a collaboration among the Danish Cancer Society Research Center, the Finnish Cancer Registry and Karolinska Institutet in Sweden.

\section{The Welfare Systems of Denmark, Finland, and Sweden}

In 2020, Denmark, Finland and Sweden had populations of 5.8, 5.5 and 10.3 million, respectively (27). The Nordic countries are well known for their generous welfare systems (28), with the core principles of solidarity and universalism and the overall aim of providing equal access for all citizens to welfare services, including health care, education and social security benefits. Decommodification in the three countries ensures that such services are provided independently of an individual's affiliation to the labour force (28). The welfare services are taxfunded and, as a result, Denmark, Finland and Sweden have some of the highest tax revenues in the world of above $40 \%$ of the gross domestic product (GDP) (29). In general, the welfare 
services provided in these countries result in a high standard of living, demonstrated for instance by high life expectancy (30).

The welfare systems of the three countries are largely comparable. Citizens are entitled to an education free of charge, from primary schooling, which is compulsory, to advanced tertiary educational levels (31). Additionally, students enrolled in tertiary education, such as college or university, may receive direct financial support and loans from the government. The unemployment rates in Denmark, Finland and Sweden are low (32) (from $5.7 \%$ to $8.8 \%$ in 2017), and few citizens rely on income support from the government (i.e. social security benefits) (32). Increasing numbers of women in the Nordic countries have entered the workforce over the past six decades (33), and the active labour force has almost equal gender distribution (32). This is to some extent enabled by supportive arrangements such as state-subsidised childcare provision, generous parental leave schemes and, often, flexible working hours $(34,35)$.

In general, all citizens of the Nordic countries have equal access to government-subsidized primary health care services provided by general practitioners and specialised health care in hospitals or provided by specialist physicians. Out-of-pocket expenses and reimbursement schemes vary, however, in the three countries (36-38). The health care services in all three countries also cover all costs directly related to the diagnosis and treatment of childhood cancer and for the vast majority of health care for any late effects. In Denmark and Sweden, more than $80 \%$ of all health care expenditure is covered by the public taxfinanced system $(36,37,39)$. In Finland, total public coverage of health care expenditures is also about $80 \%$, funded primarily through taxation (around 60\%) but also through health insurance contributions paid to the tax administration (38).

\section{Childhood Cancer Treatment in the Nordic Countries}

As childhood cancers are a heterogeneous group consisting of very different diseases, survival and developments in survival over time differ widely by cancer type (6). Since the 1970s, as a result of advances in molecular tumour biology, imaging, pharmacology, risk grouping and treatment combinations, overall five-year survival rose from $30 \%$ in the pre-chemotherapeutic era to more than $80 \%$ nowadays (6). Early collaborative clinical research to identify effective therapy for children with cancer dates back to the 1950s, when children with acute lymphoblastic leukaemia were some of the earliest participants in clinical trials of new drugs for cancer treatment (5). Participation in clinical trials is today considered the standard of paediatric cancer care, and a large number of children in Europe and North America are enrolled in protocols $(4,40-42)$ developed by collaborative study groups, such as the Nordic Society of Paediatric Haematology and Oncology (NOPHO) $(4,40,41)$.

Current therapy for some malignancies is highly intensive, and, while survival has gradually increased, the risk of treatmentrelated acute toxicity and late effects may also be increasing. The aim of many current protocols is to identify subgroups of patients for whom the intensity of therapy can be reduced to decrease toxicity.

Collaborative clinical trials to standardise childhood leukaemia treatment protocols in all Nordic countries began in 1981 (4, 40, 43), and since 1992 almost all children with leukaemia have been treated with the standardised NOPHO protocols. Treatment for lymphomas and solid tumours has been similarly standardised and is based mainly on the protocols of international collaborative study groups with NOPHO participation.

\section{Aims and Objectives of the SALiCCS Research Programme}

The SALiCCS research programme is a Nordic register-based cohort study of social and socioeconomic consequences in longterm survivors of childhood cancer in Denmark, Finland and Sweden. SALiCCS is based on the Nordic research programme Adult Life after Childhood Cancer in Scandinavia (ALiCCS), which investigates late effects of cancer therapy in children to better understand the risk and mechanisms of treatment-induced somatic disease (44). Data from ALiCCS are enriched by longitudinal information on mental disorders and social and socioeconomic outcomes after a childhood cancer diagnosis. With this strategy, the overarching goal of SALiCCS is to identify groups of childhood cancer survivors for whom early intervention would minimise later mental disorders and adverse social and socioeconomic consequences of the cancer and its treatment.

The main objectives of the SALiCCS research programme are:

i. to ascertain hospital contacts for mental disorders in childhood cancer survivors;

ii. to examine how survivors of childhood cancer transition from childhood to adulthood by determining the following social and socioeconomic conditions and attainments: scholastic achievements, attained educational level and educational delays, income, employment, occupational position and professional attainment, leaving the parental household to live independently, cohabitation with a partner, getting married and founding a family; and

iii. to assess the socioeconomic burden of childhood cancer and treatment on survivors by determining the uptake of social security benefits, such as unemployment benefits, social assistance, sickness allowance, disability pension and rehabilitation benefits.

\section{MATERIAL AND METHODS}

\section{Design and Research Setting}

The SALiCCS research programme is based on a registry-based matched cohort design. Denmark, Finland and Sweden have civil registration systems with numerous national administrative registries (45-47) that contain individual-level data in various 
fields, including cancer diagnoses (48), hospitalisation for somatic and mental disorders (49-52), vital status $(46,53)$, emigration and immigration $(45,46)$, perinatal and birth characteristics (54-56) and socio-demographic and socioeconomic characteristics (5764). Nordic citizens are assigned a unique personal identification number (Denmark since 1968, Finland since 1964 and Sweden since 1947) that is used in all national registries, enabling accurate linkage of information among registries (45-47, 65). National legislations permit and supports registry-based research. Data linkage among the registries is the basis of the SALiCCS research programme. Data from all three countries are collected and harmonized to enable pooled analyses (see section 2.5 for information on data access and data protection). Figure 1 gives an overview of the SALiCCS study design and the registers used.

The infrastructure of the population-based registers in the Nordic countries, with longstanding, high-quality, comprehensive health, socio-demographic and socioeconomic data, are an ideal, unique basis for large-scale epidemiological studies of childhood cancer survivorship. None of the Nordic countries, however, has a sufficiently large population to provide adequate statistical power for a detailed assessment of social and socioeconomic outcomes in childhood cancer survivors in a life-course perspective, particularly not for determining the underlying mechanisms of adverse social and socioeconomic outcomes and identifying particularly vulnerable groups of survivors. Combination of data from several Nordic countries is required for such purposes. As the Nordic countries have longstanding, largely standardised diagnostic and treatment procedures and similar welfare systems, it was considered reasonable to combine data on childhood cancer survivors across Nordic countries.

\section{Study Population}

The SALiCCS core population comprises all five-year survivors of a first childhood cancer (including non-malignant central nervous system tumours) diagnosed at ages 0-19 years in Denmark (1971-2008), Finland (1971-2009) and Sweden (1971-2011) (Table 1 and Figure S1). For individual SALiCCS studies however, also more broadly defined criteria for the study population may be applied (e.g. 1-year survival as eligibility criteria or including all childhood cancer cases). We identified childhood cancer cases from the respective nationwide cancer registries, which are of excellent quality and high completeness (48).

The cancer diagnoses were classified according to the International Classification of Childhood Cancer, in which tumours are classified into 12 major diagnostic groups and detailed subgroups according to the nomenclature of the International Classification of Diseases - Oncology (66-69).

We established two independent comparison groups. We randomly sampled five population-based comparisons per survivor from the populations of Denmark, Finland and Sweden from the national population registries. Survivors and population comparisons were individually matched by year of birth, sex and country of residence (and municipality of residence in Sweden) (Figure 1 and Figure S1). The second comparison group constitutes all biological full and half siblings as well as adopted (except in Finland) siblings of the childhood cancer survivors, defined as having either the same (biological or adoptive) mother or father. One sibling could serve as a sibling comparison for several survivors if more than one child in the same family was a childhood cancer survivor. We included only siblings with a maximum age difference of 10 years in order to allow meaningful comparisons of outcomes between siblings and corresponding childhood cancer survivors, leaving the possibility to reduce the age difference even more for some outcomes when relevant. Sibling and population comparisons had to be alive and not lost to follow-up five years after the reference date, and cancer-free until the age of 20 years to be eligible as comparisons. The reference date was defined as the date of diagnosis of cancer

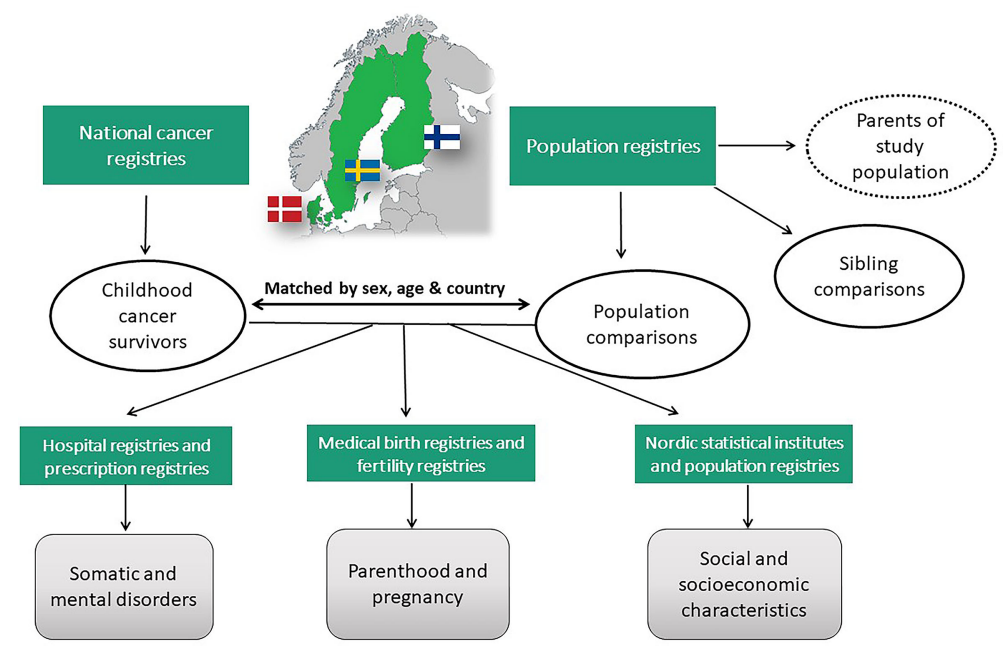

FIGURE 1 | Overview of the SALiCCS study design and data sources. 
in the corresponding matched survivor for population comparisons and, for siblings, as the date on which the sibling was of the same age as the corresponding survivor at cancer diagnosis.

As a cancer predisposition syndrome may confound associations with mental, social and socioeconomic outcomes, we excluded individuals with Down syndrome, neurofibromatosis or tuberous sclerosis, resulting in a final SALiCCS core population of 21,292 five-year childhood cancer survivors, 103,303 population comparisons and 29,644 siblings (Figure S1).

\section{Follow-Up, Social and Socioeconomic Outcomes and Information on Potential Mediators and Confounders}

The childhood cancer survivors and their comparisons were followed from five years after the cancer diagnosis or reference date until death, first emigration, loss to follow-up or end of follow-up, whichever came first. Information on end of follow-up varied somewhat by outcome data, depending on the registry used as the data source (Table 1).

For childhood cancer survivors and their comparisons, we obtained comprehensive information on highest attained education, scholastic achievements, educational delays and other educational information, individual and household disposable income, labour market affiliation, occupation position and the uptake of various social security benefits, including annual unemployment, sickness and disability benefits, social assistance and rehabilitation allowances from the social registries administered by the Nordic statistical institutes. "Disposable income" refers to annual individual and household income after taxes, including social security benefits.

Information on family structure, including cohabitation and marriage, place of residence, parenthood and other sociodemographic information, was obtained from the population registries, while data on birth characteristics were obtained from the medical birth registers, which contain mandatory, regularly updated reports on all births in the respective countries. From the national patient registries, we received comprehensive histories of hospital admissions (including outpatient contacts) for somatic and mental disorders and the respective discharge diagnoses. We obtained information on prescribed drugs from the nationwide prescribed drug registries, whereby prescription data from Finland was limited to contraceptive medications, antidepressants, pain killers, and psychiatric drugs.

Apart from diagnostic data from the national cancer registries, clinical and treatment information was overall sparse. The Finnish Cancer Registry included limited and non-validated treatment information on surgery, radiotherapy and chemotherapy (with incomplete coverage). The treatment information is given on binary level for curative, palliative or unknown intention (48). For Denmark and Sweden, some clinical and treatment data was available from the Swedish Childhood Cancer Registry and from the NOPHO database, however only for leukaemia survivors and for a limited follow-up period.

\section{Parental Information}

We collected basic socio-demographic and socioeconomic information for the biological and adoptive parents (for

TABLE 1 | Study period and data availability of parental information and information about the index subjects in the SALiCCS research programme by country.

\begin{tabular}{|c|c|c|c|}
\hline & Denmark & Finland & Sweden \\
\hline $\begin{array}{l}\text { Study period of cancer diagnosis/ } \\
\text { reference }\end{array}$ & $1971-2008$ & 1971-2009 & $1971-2011$ \\
\hline End of follow-up & 11 Aug 2017 & 31 Dec 2014 & 31 Dec 2016 \\
\hline \multicolumn{4}{|c|}{ Time period with available sociodemographic and socioeconomic information } \\
\hline Region of residence & $1980-2017$ & $1936-2016$ & $1968-2016$ \\
\hline Educational achievements & $1970-2016$ & $\begin{array}{c}\text { 1970, 1975, 1980, 1985, } \\
\text { 1987-2016 }\end{array}$ & $\begin{array}{c}1960 \\
1963-2016^{a}\end{array}$ \\
\hline Employment & $1980-2017$ & $\begin{array}{c}\text { 1970, 1975, 1980, 1985, } \\
\text { 1987-2016 }\end{array}$ & $\begin{array}{c}\text { 1960, 1965, 1970, 1975, 1980, 1985 } \\
\text { 1990-2015 }\end{array}$ \\
\hline Occupational position & $1993-2017$ & 1990, 1993, 1995, 2000, 2004-2015 & $\begin{array}{c}1960,1970,1975,1980,1985,2001- \\
2015\end{array}$ \\
\hline Disposable income & $1980-2018$ & $1995-2016$ & $\begin{array}{c}1970^{\mathrm{b}}, 1975,1985 \\
1990-2015\end{array}$ \\
\hline Social security benefits & $\begin{array}{c}1980-2016 \text { (differs between benefit } \\
\text { types) }\end{array}$ & $\begin{array}{c}\text { 1985-2016 (differs between benefit } \\
\text { types) }\end{array}$ & $\begin{array}{c}1990-2015 \text { (differs between benefit } \\
\text { types) }\end{array}$ \\
\hline Marital status & $1968-2017$ & $1970-2016$ & $1960,1965,1968-2016$ \\
\hline Cohabitation status & $1980-2017$ & $1987-2016$ & $1970,1975,1980,1985,1990-2015^{d}$ \\
\hline Parenthood & 1968-2017 & 1971-2016 & $1961-2016$ \\
\hline \multicolumn{4}{|c|}{ Time period with available information on hospital contacts for somatic and psychiatric care and prescribed drugs } \\
\hline Somatic diseases & $1977-2017$ & $1969-2014$ & $1964^{c}-2016$ \\
\hline Mental disorders & 1969-2017 & $1975-2014$ & $1973^{C}-2016$ \\
\hline Prescribed drugs & 1995-2017 & 1995-2016 & 2005-2017 \\
\hline
\end{tabular}

${ }^{a}$ Differences in the availability of educational information for the early time period.

${ }^{b}$ Net income is used in 1970 as disposable income was not available.

${ }^{c}$ Nationwide since 1987.

d1990-2015: Restricted to cohabitating couples with common children. 
Finland only for biological parents) of the childhood cancer survivors, the population comparisons, and the sibling comparisons. Furthermore, to account for the increasing number of reconstituted families in the Nordic countries, we also defined the "social parents" for the Danish and Swedish SALiCCS populations, for whom we collected the same socioeconomic and socio-demographic information as for biological parents. In Denmark, social parents were defined as individuals living at the same address with the index person the year before the reference year, at least 16 years older and not a full or half sibling of the index person. In Sweden, social parents were defined as individuals registered by Statistics Sweden as a parent or guardian in the same household in which the index person was defined, the year before the reference date. Social parents could be identified from 1980 onwards in Denmark and from 1990 onwards in Sweden. Corresponding information was not collected for the Finnish SALiCCS population.

\section{Data Access, Data Protection and Other Ethical Considerations}

The SALiCCS research programme has been approved by Statistics Denmark, the Regional Ethical Review Board in Stockholm, Sweden (dnr 2016/25-31/5, 2016/1561-32, 2017/ 1656-32, 2017/1990-32, 2017/2340-32, 2018/1165-32), Findata (Dnro THL/5543/14.06.00/2020) prolonging the former approvals by the National Institute for Health and Welfare and Social Insurance (KELA) and Statistics Finland (TK-53-394-17) in Finland. For the European Union General Data Protection Regulation (GDPR), the SALiCCS project is listed in a local archive (2018-DCRC-0044) at the Danish Cancer Society Research Center, which provides an accurate, updated overview of ongoing projects and of ongoing research projects involving personal data under the GDPR. The 2018-DCRC-0044 replaces the former notification from the Danish Data Protection Agency.

The SALiCCS research programme is conducted in compliance with the requirements of the GDPR and other applicable laws in the respective countries, as well as the respective procedures at Statistics Denmark, the Danish Cancer Society Research Center, Karolinska Institutet and the Finnish Cancer Registry. All data have been stored, linked and pooled and are analysed at a secure remote platform at Statistics Denmark, with controlled remote access only for individually approved SALiCCS project members. Personal identification numbers were replaced by pseudonymised ID numbers, and the key code is kept only by the original register holders or at the respective statistical institutes. All the results of the statistical analyses will only be presented as aggregated data.

\section{SPECIFIC CHARACTERISTICS OF THE STUDY POPULATION}

The core SALiCCS population comprises 21,292 five-year survivors, 103,303 population comparisons and 29,644 siblings as the second comparison group. The distribution of diagnostic characteristics differed only slightly in Denmark, Finland and Sweden (Table 2). The most common diagnoses were tumours of the central nervous system (23\%), leukaemias (23\%) and lymphomas (15\%). Slightly over half of the childhood cancer survivors were male (53\%), 31\% were diagnosed before the age of 5 years, and about $60 \%$ were diagnosed between 1990 and 2009. The length of follow-up after the date of cancer diagnosis ranged from 5.0 to 46.6 years, with a median follow-up time of 20.7 years in Denmark, 19.1 years in Finland and 20.6 years in Sweden (Table 2).

The SALiCCS core population is defined by individuals who survived the five-year survival point. To describe this population, the survival probabilities of all children diagnosed with cancer in Denmark, Finland and Sweden, their population comparisons and siblings are shown in Figure 2 (including children who died or emigrated within the first five years of diagnosis/reference date) and a comparison of the distribution of diagnostic groups and specific cancer types between all incident childhood cancer cases in Denmark, Finland and Sweden and the SALiCCS 5-year childhood cancer survivors is given in Table S1. Overall survival figures for this extended population are also given by diagnostic decade, age at diagnosis, diagnostic group and country (Figure 2 and Supplementary Material S2-S5). We intentionally excluded any adverse social and socioeconomic conditions that may have arisen while being hospitalised and receiving cancer treatment by starting follow-up at five years after the childhood cancer diagnosis, since these acute and direct outcomes would not reflect the social and socioeconomic consequences in longterm survivors.

Tables 3 and S2 present the distribution of sociodemographic characteristics in the SALiCCS core population, consisting of all individuals who survived five years after diagnosis or the respective reference date for comparisons. The distribution of place of residence, parental age and parental socioeconomic characteristics differed only slightly for childhood cancer survivors and population and sibling comparisons (Table 3).

This SALiCCS core population will serve as the basis for individual studies of the objectives of the SALiCCS research programme, as outlined in section 1.3. Additional inclusion and exclusion criteria may be applied to the core population in individual SALiCCS studies, which may be restricted to specific time periods, depending on the respective research objectives and register coverage.

\section{DISCUSSION}

The growing number of survivors of childhood cancers diagnosed at a young age, with many years of life ahead, indicates the increasing clinical and public health relevance of investigating the long-term social and socioeconomic consequences of the cancer diagnosis and the life-saving treatment. Some previous evidence points to higher risks of impaired social functioning and adverse socioeconomic outcomes in adult life. Nevertheless, additional research is urgently required to fully understand the long-term social consequences of a diagnosis of cancer in 
TABLE 2 | Characteristics of 5-year childhood cancer survivors diagnosed in 1971-2008 (DEN), 2009 (FIN), 2011 (SWE) by country and for the three countries combined.

\begin{tabular}{|c|c|c|c|c|c|c|c|c|}
\hline & \multicolumn{2}{|c|}{ Denmark } & \multicolumn{2}{|c|}{ Finland } & \multicolumn{2}{|c|}{ Sweden } & \multicolumn{2}{|c|}{ Three-Country Wide pooled data } \\
\hline & $N$ & $\%$ & $N$ & $\%$ & $N$ & $\%$ & $N$ & $\%$ \\
\hline Total & 5343 & & 5672 & & 10277 & & 21292 & \\
\hline \multicolumn{9}{|l|}{ Sex } \\
\hline Boys & 3000 & 56.1 & 2939 & 51.8 & 5405 & 52.6 & 11344 & 53.3 \\
\hline Girls & 2343 & 43.9 & 2733 & 48.2 & 4872 & 47.4 & 9948 & 46.7 \\
\hline \multicolumn{9}{|l|}{ Age at diagnosis (years) } \\
\hline$<1$ & 306 & 5.7 & 377 & 6.7 & 607 & 5.9 & 1290 & 6.1 \\
\hline $1-4$ & 1294 & 24.2 & 1434 & 25.3 & 2475 & 24.1 & 5203 & 24.4 \\
\hline $5-9$ & 964 & 18.0 & 948 & 16.7 & 1844 & 17.9 & 3756 & 17.6 \\
\hline $10-14$ & 1046 & 19.6 & 1106 & 19.5 & 2005 & 19.5 & 4157 & 19.5 \\
\hline $15-19$ & 1733 & 32.4 & 1807 & 31.9 & 3346 & 32.6 & 6886 & 32.3 \\
\hline \multicolumn{9}{|l|}{ Decade of diagnosis } \\
\hline $1971-1979$ & 824 & 15.4 & 797 & 14.1 & 1578 & 15.4 & 3199 & 15.0 \\
\hline $1980-1989$ & 1259 & 23.6 & 1316 & 23.2 & 2408 & 23.4 & 4983 & 23.4 \\
\hline $1990-1999$ & 1592 & 29.8 & 1765 & 31.1 & 2841 & 27.6 & 6198 & 29.1 \\
\hline $2000-2009$ & 1668 & 31.2 & 1794 & 31.6 & 2803 & 27.3 & 6265 & 29.4 \\
\hline $2010-2011$ & - & - & - & - & 647 & 6.3 & 647 & 3.0 \\
\hline \multicolumn{9}{|l|}{ Decade of birth } \\
\hline $1951-1959$ & 182 & 3.4 & 235 & 4.1 & 440 & 4.3 & 857 & 4.0 \\
\hline $1960-1969$ & 722 & 13.5 & 645 & 11.4 & 1285 & 12.5 & 2652 & 12.5 \\
\hline $1970-1979$ & 1342 & 25.1 & 1310 & 23.1 & 2377 & 23.1 & 5029 & 23.6 \\
\hline $1980-1989$ & 1508 & 28.2 & 1728 & 30.5 & 2659 & 25.9 & 5895 & 27.7 \\
\hline $1990-1999$ & 1178 & 22.1 & 1270 & 22.4 & 2427 & 23.6 & 4875 & 22.9 \\
\hline $2000-2009$ & 411 & 7.7 & 484 & 8.5 & 1048 & 10.2 & 1943 & 9.1 \\
\hline $2010-2011$ & - & - & - & - & 41 & 0.4 & 41 & 0.2 \\
\hline \multicolumn{9}{|l|}{ Cancer type ${ }^{a}$} \\
\hline Leukaemias & 1189 & 22.3 & 1382 & 24.4 & 2324 & 22.6 & 4895 & 23.0 \\
\hline Lymphoid leukaemia ${ }^{b}$ & 1000 & 18.7 & 1170 & 20.6 & 1895 & 18.4 & 4065 & 19.1 \\
\hline Acute myeloid leukaemia ${ }^{c}$ & 134 & 2.5 & 130 & 2.3 & 235 & 2.3 & 499 & 2.3 \\
\hline Other leukaemia & 55 & 1.0 & 82 & 1.5 & 194 & 1.9 & 331 & 1.6 \\
\hline Lymphomas & 759 & 14.2 & 952 & 16.8 & 1465 & 14.3 & 3176 & 14.9 \\
\hline Hodgkin lymphoma ${ }^{d}$ & 440 & 8.2 & 569 & 10.0 & 813 & 7.9 & 1822 & 8.6 \\
\hline Non-Hodgkin lymphoma ${ }^{e}$ & 196 & 3.7 & 364 & 6.4 & 213 & 2.1 & 773 & 3.6 \\
\hline Other lymphoma & 123 & 2.3 & 19 & 0.3 & 439 & 4.3 & 581 & 2.7 \\
\hline CNS tumours $^{\dagger}$ & 1277 & 23.9 & 1110 & 19.6 & 2524 & 24.6 & 4911 & 23.1 \\
\hline Ependymoma & 103 & 1.9 & 110 & 1.9 & 230 & 2.2 & 443 & 2.1 \\
\hline Astrocytoma and other gliomas & 510 & 10.0 & 697 & 12.3 & 1088 & 10.6 & 2295 & 10.8 \\
\hline Embryonal CNS tumours & 130 & 2.4 & 108 & 1.9 & 384 & 3.7 & 622 & 2.9 \\
\hline Other specified or unspecified CNS tumour & 534 & 10.0 & 195 & 3.4 & 822 & 8.0 & 1551 & 7.3 \\
\hline Sympathetic nervous system tumours & 169 & 3.2 & 209 & 3.7 & 244 & 2.4 & 622 & 2.9 \\
\hline Retinoblastomas & 148 & 2.8 & 124 & 2.2 & 226 & 2.2 & 498 & 2.3 \\
\hline Renal tumours & 232 & 4.3 & 273 & 4.8 & 487 & 4.7 & 992 & 4.7 \\
\hline Hepatic tumours & 35 & 0.7 & 35 & 0.6 & 80 & 0.8 & 150 & 0.7 \\
\hline Malignant bone tumours & 180 & 3.4 & 202 & 3.6 & 396 & 3.9 & 778 & 3.7 \\
\hline Soft tissue sarcomas & 276 & 5.2 & 315 & 5.6 & 488 & 4.8 & 1079 & 5.1 \\
\hline Germ cell tumours & 466 & 8.7 & 322 & 5.7 & 642 & 6.3 & 1430 & 6.7 \\
\hline Malignant epithelial neoplasms & 533 & 10.0 & 676 & 11.9 & 1110 & 10.8 & 2319 & 10.9 \\
\hline Other \& unspecified malignant neoplasms & 79 & 1.5 & 72 & 1.3 & 291 & 2.8 & 442 & 2.1 \\
\hline \multicolumn{9}{|c|}{ Secondary malignancy before age of 20 years } \\
\hline Yes & 66 & 1.2 & 65 & 1.2 & 101 & 1.0 & 232 & 1.1 \\
\hline No & 5277 & 98.8 & 5607 & 98.8 & 10176 & 99.0 & 21060 & 98.9 \\
\hline \multicolumn{9}{|l|}{ End event } \\
\hline Death & 569 & 10.7 & 542 & 9.6 & 831 & 8.1 & 1942 & 9.1 \\
\hline Emigration ( $1^{\text {st }}$ emigration) & 391 & 7.3 & 59 & 1.0 & 433 & 4.2 & 883 & 4.2 \\
\hline Lost to follow-up & 5 & 0.1 & 0 & 0 & 0 & 0 & 5 & $<0.1$ \\
\hline End of study & 4378 & 81.9 & 5071 & 89.4 & 9013 & 87.7 & 18462 & 86.7 \\
\hline DEN: 11 Aug 2017 & & & & & & & & \\
\hline
\end{tabular}




\begin{tabular}{|c|c|c|c|c|c|c|c|c|}
\hline & \multicolumn{2}{|c|}{ Denmark } & \multicolumn{2}{|c|}{ Finland } & \multicolumn{2}{|c|}{ Sweden } & \multicolumn{2}{|c|}{ Three-Country Wide pooled data } \\
\hline \multicolumn{9}{|l|}{ SWE: 31 Dec 2016} \\
\hline Median time of follow-up in years (range) & $\begin{array}{c}20.7 \\
(5.0-46.6)\end{array}$ & & $\begin{array}{c}19.1 \\
(5.0-44.0)\end{array}$ & & $\begin{array}{c}20.6 \\
(5.0-46.0)\end{array}$ & & $\begin{array}{c}20.1 \\
(5.0-46.6)\end{array}$ & \\
\hline
\end{tabular}

No missing information for any of the characteristics given in this table.

${ }^{a}$ Classified by the International Classification of Childhood Cancer.

${ }^{b}$ Lymphoid leukaemia defined as ICCC1 group I a-b and ICCC3 group la.

${ }^{C}$ Acute myeloid leukaemia defined as ICCC1 group Ic and ICCC3 group Ib.

${ }^{d}$ Hodgkin lymphoma defined as ICCC1 and ICCC3 group Ila.

${ }^{e}$ Non-Hodgkin lymphoma defined as ICCC1 and ICCC3 group IIb.

${ }^{f}$ CNS tumor subtypes were grouped as follows: Ependymoma (defined by ICCC 1 and ICCC3 group 3a), astrocytoma and other gliomas (ICCC 1 and ICCC 3 groups 3b and $3 d$ combined), and embryonal CNS tumours (defined by ICCC 1 and ICCC 3 group 3C).

childhood, to identify vulnerable survivors at particular risk for adverse social and socioeconomic impairments in adulthood and ultimately to provide scientific knowledge for evidenced-based survivorship care that addresses not only somatic late effects but also psychosocial impairments.

Data linkage among various population-based registries in Denmark, Finland and Sweden gave us the unique possibility of setting up the largest, most comprehensive population-based research initiative on the social and socioeconomic consequences of childhood cancer so far, comprising more than 21,000 fiveyear childhood cancer survivors and two independent comparison groups. The large number of survivors will enable detailed analyses, allowing for identification of vulnerable subgroups in terms of e.g. diagnostic or socio-demographic characteristics. Use of high-quality population-based register data with high coverage, virtually no loss to follow-up and no self-reporting or non-participation allows reliable estimation of the social and socioeconomic outcomes with minimal risk of bias in countries with similar welfare systems and generally equal access to education and other services. Particularly valuable strengths of the SALiCCS research programme include annual information on social and socioeconomic outcomes, facilitating the study of trajectories and enabling a comprehensive long-term follow-up, as well as the availability of detailed information on hospital contacts, allowing stratified analyses by somatic or mental late effects. A limitation of the SALiCCS research programme is the lack of comprehensive and threecountrywide information on cancer treatment and other relevant clinical characteristics such as subtype of disease and tumour stage or grade. Such information would have been of considerable value for assessing the underlying mechanisms leading to adverse social and socioeconomic conditions, and to identify survivors of childhood cancer that are particularly vulnerable to adverse outcomes. For instance, especially cranial radiation therapy has been associated with various somatic late effects, including long-term neurocognitive impairment, as well as with adverse educational attainments, higher risk of unemployment and low income (22). Understanding the causal
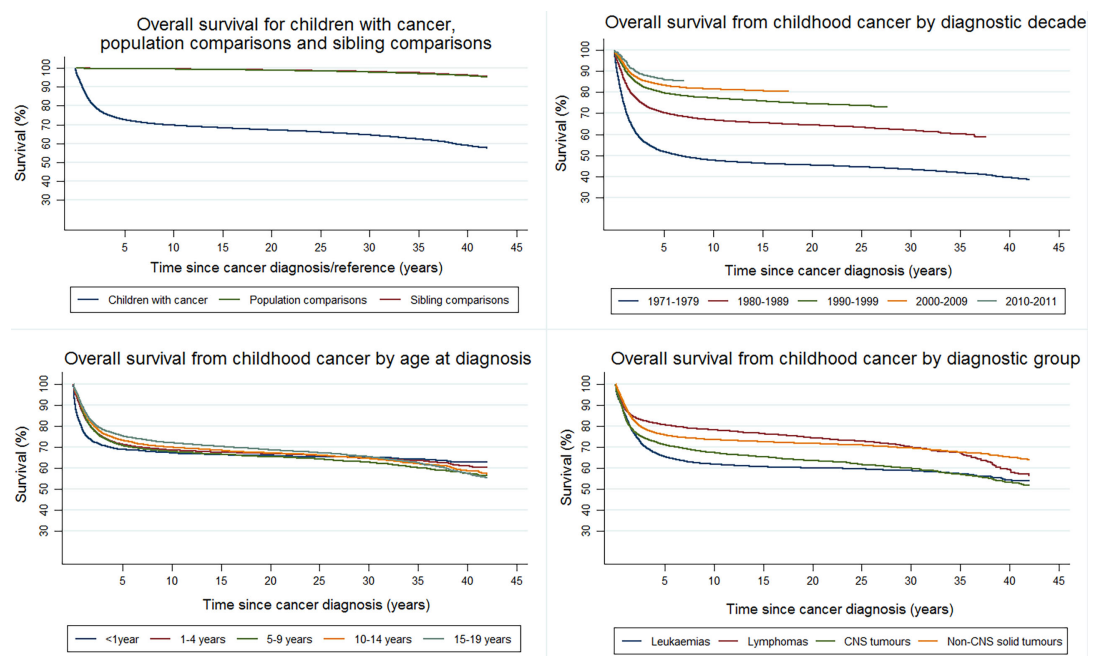

FIGURE 2 | Overall survival in the SALiCCS population: by children with cancer, population comparisons and siblings, by diagnostic decade, by age at diagnosis and by diagnostic group. 
TABLE 3 | Sociodemographic and socioeconomic characteristics of 5-year childhood cancer survivors, population comparisons and siblings, pooled data from the three Nordic countries.

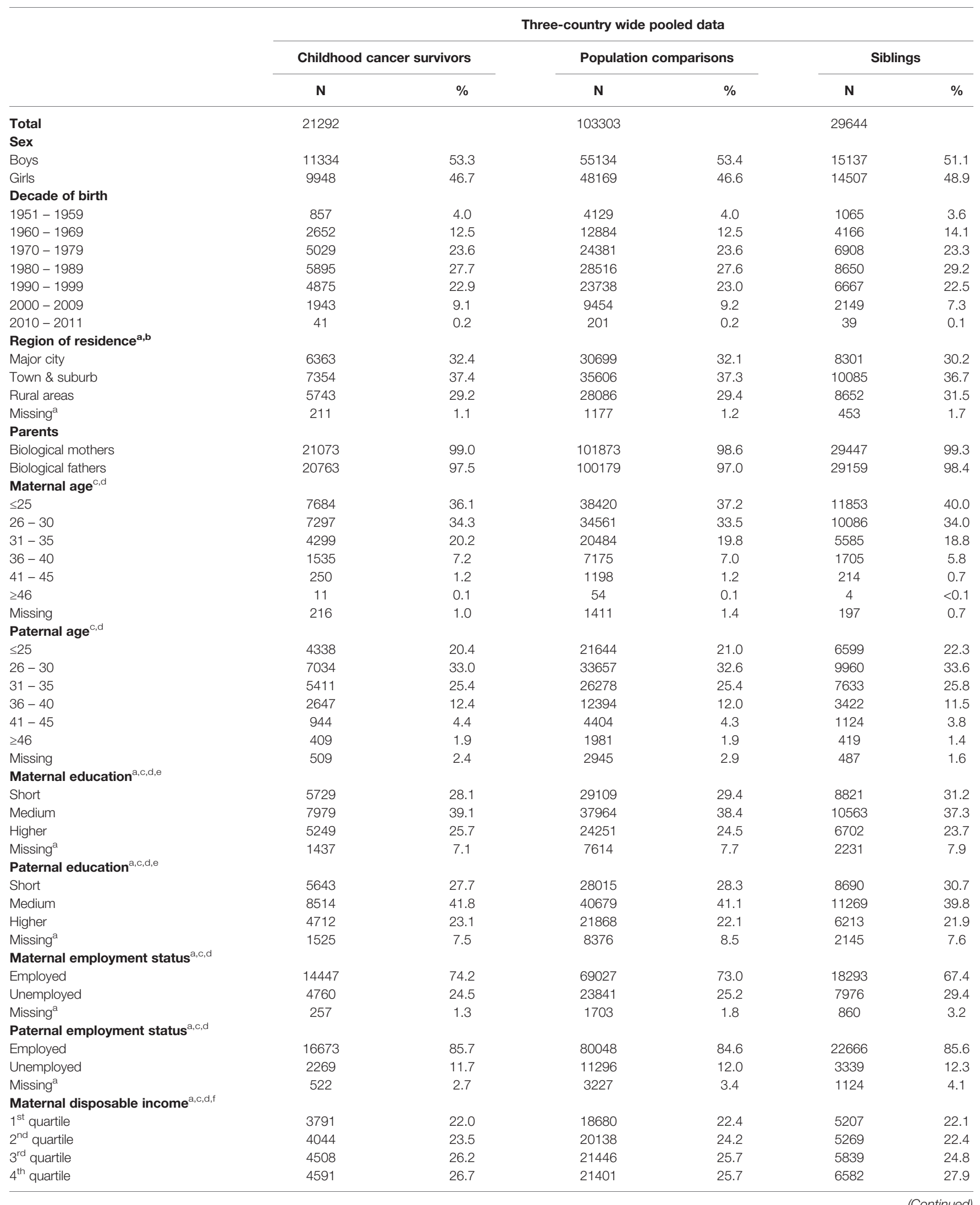




\begin{tabular}{|c|c|c|c|c|c|c|}
\hline & \multicolumn{6}{|c|}{ Three-country wide pooled data } \\
\hline & $\mathbf{N}$ & $\%$ & $\mathbf{N}$ & $\%$ & $\mathbf{N}$ & $\%$ \\
\hline Missing $^{a}$ & 266 & 1.6 & 1686 & 2.0 & 678 & 2.9 \\
\hline \multicolumn{7}{|l|}{ Paternal disposable income $e^{a, c, d, f}$} \\
\hline $1^{\text {st }}$ quartile & 3732 & 21.7 & 18892 & 22.7 & 5353 & 22.7 \\
\hline $4^{\text {th }}$ quartile & 4458 & 25.9 & 20149 & 24.2 & 5861 & 24.9 \\
\hline Missing $^{a}$ & 511 & 3.0 & 3049 & 3.7 & 886 & 3.8 \\
\hline \multicolumn{7}{|c|}{ Average days/year with hospital visit ${ }^{g}$} \\
\hline & \multicolumn{2}{|c|}{ Average days/year } & \multicolumn{2}{|c|}{ Average days/year } & \multicolumn{2}{|c|}{ Average days/year } \\
\hline $0-4$ years after reference date & \multicolumn{2}{|c|}{18.2} & \multicolumn{2}{|c|}{0.8} & \multicolumn{2}{|c|}{0.9} \\
\hline 5-9 years after reference date & \multicolumn{2}{|l|}{6.2} & \multicolumn{2}{|l|}{1.0} & \multicolumn{2}{|l|}{1.1} \\
\hline 35-39 years after reference date & 5.5 & & 1.8 & & 2.4 & \\
\hline End event & & & & & & \\
\hline Death & 1942 & 9.1 & 1416 & 1.4 & 389 & 1.3 \\
\hline Emigration ( $1^{\text {st }}$ emigration) & 883 & 4.2 & 5606 & 5.4 & 1526 & 5.2 \\
\hline Lost to follow-up & 5 & $<0.1$ & 26 & $<0.1$ & 3 & $<0.1$ \\
\hline End of study & 18462 & 86.7 & 96255 & 93.2 & 27726 & 93.5 \\
\hline DEN: 11 Aug 2017 & & & & & & \\
\hline SWE: 31 Dec 2016 & & & & & & \\
\hline FIN: 31 Dec 2014 & & & & & & \\
\hline Median time of follow-up (years) & 20.1 & & 21.4 & & 22.1 & \\
\hline & $(5.0-46.6)$ & & $(5.0-46.6)$ & & $(5.0-46.6)$ & \\
\hline Type of sibling $^{h}$ & & & & & & \\
\hline
\end{tabular}

Reference date corresponds to the date of diagnosis for the population comparisons. For siblings the reference date corresponds to the date when a sibling was of the same age as the respective survivor at diagnosis.

aInformation tied to the years of register coverage in the respective country (see Table 1). Parental socioeconomic information from Finland were tied to the years from 1980 onwards.

${ }^{b}$ Corresponds to reference year.

${ }^{\circ}$ Characteristics correspond to the biological parents.

${ }^{d}$ Corresponds to the year before reference year; if not available, then to the year closest to the year before reference year.

${ }^{\circledR}$ Parental highest education was grouped into short [early childhood education, primary and lower secondary education, ISCED levels 0-2], medium [upper secondary including vocational upper secondary education, ISCED level 3] and higher [ISCED level 4-8] education, following the International Standard Classification of Education (ISCED). Parents with missing education in Finland have been allocated to lowest education category, as only education from secondary level and above is registered in Finland.

${ }^{f}$ Annual disposable income was categorised into four groups based on the sex- and calendar-year specific income distribution (quartiles) of the population comparisons in the respective country. ${ }^{9}$ Average number of days/year with inpatient and outpatient hospital contact for any somatic and mental disorders during 5-year periods after reference date.

${ }^{h}$ Adoptive siblings from Sweden were assigned to the group offull siblings, whereas adoptive siblings from Denmark cannot be specifically identified and therefore may be found in both groups.

pathway of those adverse outcomes would be of substantial clinical and public health relevance. We do, however, have information on hospital contacts, including the full history, with dates of in- and outpatient hospital contacts including corresponding diagnoses, which may be used in some individual SALiCCS studies as indicators of severity of disease, length of treatment and disease burden.

The novel findings resulting from this research programme may serve as a basis for recommendations on interventions for vulnerable subgroups of survivors. Such recommendations may not be limited to the Nordic countries, with their extensive welfare systems, but may also be applicable to other countries, especially within Europe.

\section{DATA AVAILABILITY STATEMENT}

The data that support the information of this manuscript were accessed remotely on a secure platform at Statistics Denmark. Pseudonymised individual-level data were obtained from national registry holders after ethical approval (where applicable) and secrecy assessment. According to Danish, 
Finnish and Swedish laws and regulations, individual-level sensitive data can only be made available for researchers who fulfil legal requirements for access to personal sensitive data. Please contact Jeanette Falck Winther (jeanette@cancer.dk), the Principal Investigator of the SALiCCS research programme, for further questions about data access.

\section{ETHICS STATEMENT}

The SALiCCS research programme has been approved by Statistics Denmark, the Regional Ethical Review Board in Stockholm, Sweden (dnr 2016/25-31/5, 2016/1561-32, 2017/ 1656-32, 2017/1990-32, 2017/2340-32, 2018/1165-32), Findata (Dnro THL/5543/14.06.00/2020) prolonging the former approvals by the National Institute for Health and Welfare and Social Insurance (KELA) and Statistics Finland (TK-53-394-17) in Finland. For the European Union General Data Protection Regulation (GDPR), the SALiCCS project is listed in a local archive (2018-DCRC-0044) at the Danish Cancer Society Research Center, which provides an accurate, updated overview of ongoing projects and of ongoing research projects involving personal data under the GDPR. The 2018-DCRC-0044 replaces the former notification from the Danish Data Protection Agency.

\section{AUTHOR CONTRIBUTIONS}

FE and JW developed the concept and outline of the manuscript. All authors contributed to the acquisition and preparation of data. FE, LF, HM, NM, L-MM-H, MF, and JW developed the strategy for the descriptive analysis and presentation of the study population. FE, LF, HM, and JW drafted the manuscript. All authors provided critical feedback, critically reviewed the manuscript for important intellectual content, and revised the manuscript. All authors approved the final manuscript as submitted and agreed to be accountable for all aspects of the work.

\section{FUNDING}

This work was supported by NordForsk under grant 76111, the Danish Childhood Cancer Foundation under grant 2016-0293, Aarhus University under fellowship 43239402, the Swiss

\section{REFERENCES}

1. The European Society for Paediatric Oncology (SIOPE). The SIOPE Strategic Plan - a European Cancer Plan for Children and Adolescents. Brussels, Belgium (2015).

2. Schuz J, Erdmann F. Environmental Exposure and Risk of Childhood Leukemia: An Overview. Arch Med Res (2016) 47:607-14. doi: 10.1016/j.arcmed.2016.11.017

3. Spector LG, Pankratz N, Marcotte EL. Genetic and Nongenetic Risk Factors for Childhood Cancer. Pediatr Clinics North Am (2015) 62:11-25. doi: 10.1016/j.pcl.2014.09.013

4. Schmiegelow K, Forestier E, Hellebostad M, Heyman M, Kristinsson J, Soderhall S, et al. Long-Term Results of NOPHO ALL-92 and ALL-2000
National Science Foundation under grant P2LUP3_175288 (personal fellowship to LM), the Tømrermester Jørgen Holm og Hustru Elisa F. Hansens Mindelegat under grant 20088 and the Swedish Childhood Cancer Foundation under grant PR20200130. The funding sources had no involvement in the content or preparation of the manuscript.

\section{ACKNOWLEDGMENTS}

The authors are grateful to Anja Krøyer (Danish Cancer Society Research Center, Childhood Cancer Research Group) for her technical support with data acquisition and preparation.

\section{SUPPLEMENTARY MATERIAL}

The Supplementary Material for this article can be found online at: https://www.frontiersin.org/articles/10.3389/fonc.2021.752948/ full\#supplementary-material

Supplementary Figure 1 | Flow diagram of the sampling of the SALiCCS core population.

Supplementary Figure 2 | Overall survival for children with cancer, population comparisons and sibling, for the entire SALiCCS population and by country (reference date in 1971-2008 (DEN), 2009 (FIN), 2011 (SWE)).

Supplementary Figure 3 | Overall survival from childhood cancer by diagnostic decade, for the entire SALiCCS population and by country (children diagnosed with cancer in 1971-2008 (DEN), 2009 (FIN), 2011 (SWE)).

Supplementary Figure 4 | Overall survival from childhood cancer by age at diagnosis, for the entire SALiCCS population and by country (children diagnosed with cancer in 1971-2008 (DEN), 2009 (FIN), 2011 (SWE)).

Supplementary Figure 5 | Overall survival from childhood cancer by diagnostic group, for the entire SALiCCS population and by country (children diagnosed with cancer in 1971-2008 (DEN), 2009 (FIN), 2011 (SWE)).

Supplementary Figure 6 | Overall survival from childhood non-CNS solid tumours by tumour type, for the entire SALiCCS population and by country (children diagnosed with cancer in 1971-2008 (DEN), 2009 (FIN), 2011 (SWE)).

Supplementary Table 1 | Comparison of the distribution of diagnostic groups and specific cancer types between all incident childhood cancer cases and the SALiCCS 5-year childhood cancer survivors.

Supplementary Table 2 | Sociodemographic and socioeconomic characteristics of 5-year childhood cancer survivors, population comparisons and siblings by country. 24:345-54. doi: 10.1038/leu.2009.251

5. Pritchard-Jones K, Pieters R, Reaman GH, Hjorth L, Downie P, Calaminus G, et al. Sustaining Innovation and Improvement in the Treatment of Childhood Cancer: Lessons From High-Income Countries. Lancet Oncol (2013) 14:e95103. doi: 10.1016/S1470-2045(13)70010-X

6. Gatta G, Botta L, Rossi S, Aareleid T, Bielska-Lasota M, Clavel J, et al. Childhood Cancer Survival in Europe 1999-2007: Results of EUROCARE-5-A PopulationBased Study. Lancet Oncol (2014) 15:35-47. doi: 10.1016/S1470-2045(13)70548-5

7. Allemani C, Matsuda T, Di Carlo V, Harewood R, Matz M, Niksic M, et al. Global Surveillance of Trends in Cancer Survival 2000-14 (CONCORD-3): 
Analysis of Individual Records for 37513025 Patients Diagnosed With One of 18 Cancers From 322 Population-Based Registries in 71 Countries. Lancet (2018) 391:1023-75. doi: 10.1016/S0140-6736(17)33326-3

8. Erdmann F, Frederiksen LE, Bonaventure A, Mader L, Hasle H, Robison LL, et al. Childhood Cancer: Survival, Treatment Modalities, Late Effects and Improvements Over Time. Cancer Epidemiol (2021) 71(Pt B):101733. doi: 10.1016/j.canep.2020.101733

9. Erdmann F, Ghantous A, Schüz J. Environmental Agents and Childhood Cancer. In: Nriagu J, editor. Encyclopedia of Environmental Health. 2. Burlington: Elsevier B.V. (2019). p. 336-47.

10. Bhatia S, Armenian SH, Armstrong GT, van Dulmen-den Broeder E, Hawkins MM, Kremer LC, et al. Collaborative Research in Childhood Cancer Survivorship: The Current Landscape. J Clin Oncol (2015) 33:3055-64. doi: 10.1200/JCO.2014.59.8052

11. Hudson MM, Armenian SH, Armstrong GT, Chow EJ, Henderson TO. Optimization of Health and Extension of Lifespan Through Childhood Cancer Survivorship Research. J Clin Oncol (2018) 36(21):2133-4. doi: 10.1200/JCO.2018.79.0477

12. Norsker FN, Pedersen C, Armstrong GT, Robison LL, McBride ML, Hawkins M, et al. Late Effects in Childhood Cancer Survivors: Early Studies, Survivor Cohorts, and Significant Contributions to the Field of Late Effects. Pediatr Clinics North America (2020) 67:1033-49. doi: 10.1016/j.pcl.2020.07.002

13. Oeffinger K, Mertens AC, Sklar CA, Kawashima T, Hudson MM, Meadows AT, et al. Chronic Health Conditions in Adult Survivors of Childhood Cancer. N Engl J Med (2006) 355(15):1572-82. doi: 10.1056/NEJMsa060185

14. Geenen MM, Cardous-Ubbink MC, Kremer LC, van den Bos C, van der Pal HJ, Heinen RC, et al. Medical Assessment of Adverse Health Outcomes in Long-Term Survivors of Childhood Cancer. JAMA (2007) 297:2705-15. doi: 10.1001/jama.297.24.2705

15. de Fine Licht S, Rugbjerg K, Gudmundsdottir T, Bonnesen TG, Asdahl PH, Holmqvist AS, et al. Long-Term Inpatient Disease Burden in the Adult Life After Childhood Cancer in Scandinavia (ALiCCS) Study: A Cohort Study of 21,297 Childhood Cancer Survivors. PloS Med (2017) 14:e1002296. doi: 10.1371/journal.pmed.1002296

16. Fidler MM, Reulen RC, Winter DL, Kelly J, Jenkinson HC, Skinner R, et al. Long Term Cause Specific Mortality Among 34489 Five Year Survivors of Childhood Cancer in Great Britain: Population Based Cohort Study. Bmj (2016) 354:i4351. doi: 10.1136/bmj.i4351

17. Olsen JH, Moller T, Anderson H, Langmark F, Sankila R, Tryggvadottir L, et al. Lifelong Cancer Incidence in 47,697 Patients Treated for Childhood Cancer in the Nordic Countries. J Natl Cancer Inst (2009) 101:806-13. doi: 10.1093/jnci/djp104

18. Robison LL, Hudson MM. Survivors of Childhood and Adolescent Cancer: Life-Long Risks and Responsibilities. Nat Rev Cancer (2014) 14:61-70. doi: $10.1038 / \mathrm{nrc} 3634$

19. Lund LW, Winther JF, Dalton SO, Cederkvist L, Jeppesen P, Deltour I, et al. Hospital Contact for Mental Disorders in Survivors of Childhood Cancer and Their Siblings in Denmark: A Population-Based Cohort Study. Lancet Oncol (2013) 14:971-80. doi: 10.1016/S1470-2045(13)70351-6

20. Nathan PC, Nachman A, Sutradhar R, Kurdyak P, Pole JD, Lau C, et al. Adverse Mental Health Outcomes in a Population-Based Cohort of Survivors of Childhood Cancer. Cancer (2018) 124:2045-57. doi: 10.1002/cncr.31279

21. Lund LW, Winther JF, Cederkvist L, Andersen KK, Dalton SO, Appel CW, et al. Increased Risk of Antidepressant Use in Childhood Cancer Survivors: A Danish Population-Based Cohort Study. Eur J Cancer (2015) 51:675-84. doi: 10.1016/j.ejca.2015.01.001

22. Frederiksen LE, Mader L, Feychting M, Mogensen H, Madanat-Harjuoja L, Malila N, et al. Surviving Childhood Cancer: A Systematic Review of Studies on Risk and Determinants of Adverse Socioeconomic Outcomes. Int J Cancer (2019) 144(8):1796-823. doi: 10.1002/ijc.31789

23. Mader L, Michel G, Roser K. Unemployment Following Childhood Cancer. Dtsch Arztebl Int (2017) 114:805-12. doi: 10.3238/arztebl.2017.0805

24. Kirchhoff AC, Leisenring W, Krull KR, Ness KK, Friedman DL, Armstrong GT, et al. Unemployment Among Adult Survivors of Childhood Cancer: A Report From the Childhood Cancer Survivor Study. Med Care (2010) 48:1015-25. doi: 10.1097/MLR.0b013e3181eaf880

25. Pang JW, Friedman DL, Whitton JA, Stovall M, Mertens AC, Robison LL, et al. Employment Status Among Adult Survivors in the Childhood Cancer
Survivor Study. Pediatr Blood Cancer (2008) 50:104-10. doi: 10.1002/ pbc. 21226

26. Erdmann F, Feychting M, Mogensen H, Schmiegelow K, Zeeb H. Social Inequalities Along the Childhood Cancer Continuum: An Overview of Evidence and a Conceptual Framework to Identify Underlying Mechanisms and Pathways. Front Public Health (2019) 7:84. doi: 10.3389/fpubh. 2019.00084

27. Nordic Co-operation. Nordic Statistics Database. (2021).

28. Esping-Andersen G. The Three Worlds of Welfare Capitalism. Princeton, New Jersey: Princeton University Press (1990).

29. OECD. Revenue Statistics 2018 - Tax Revenue Trends in the OECD (2018). Available at: http://www.oecd.org/tax/revenue-statistics-2522770x.htm.

30. OECD. Life Expectancy at Birth (Indicator), Both Genders 1960-2017. (2019). doi: $10.1787 / 27 \mathrm{e} 0 \mathrm{fc} 9 \mathrm{~d}-\mathrm{en}$

31. OECD. Education at a Glance 2018: OECD Indicators. Paris: OECD Publishing (2018). doi: 10.1787/eag-2018-en.

32. Agerskov U, Mertsola SN.C.o. Ministers, Nordic Statistics 2018. Copenhagen, Denmark: Nordic Council of Ministers (2018). Available at: http://norden. diva-portal.org/smash/get/diva2:1257993/FULLTEXT01.pdf.

33. OECD. Labour Force (Indicator) - Labour Force Women, 1959-2017. (2019). doi: 10.1787/ef2e7159-en

34. OECD. Family Benefits Public Spending (Indicator), 1980-2017. (2019). doi: $10.1787 / 8 \mathrm{e} 8 \mathrm{~b} 3273$-en

35. Lammi-Taskula J, Brandth B, Duvander A-Z, V. Gíslason I, Björk Eydal G, Rostgaard T. Parental Leave, Childcare and Gender Equality in the Nordic Countries. Copenhagen: Nordic Council of Ministers (2012). doi: 10.6027/ TN2011-562

36. Olejaz M, Nielsen AJ, Rudkjøbing A, Birk HO, Krasnik A, HernandezQuevedo C. Denmark - Health System Review, Health Systems in Transition. Copenhagen: World Health Organization (2012). 14(2):1-192.

37. Annel A, Glenngaard AH, Merkur S. Sweden - Health System Review, Health Systems in Transition. Vol. 14, no. 5. Copenhagen: World Health Organization (2012). p. 1-159.

38. Vuorenkoski L. Finland - Health System Review, Health Systems in Transition. Vol. 10, no. 4. Copenhagen: World Health Organization (2008). p. 1-168.

39. OECD. Health a Glance 2017 - OECD Indicators. Paris: OECD Publishing (2017). doi: 10.1787/health_glance-2017-en

40. Lie SO, Abrahamsson J, Clausen N, Forestier E, Hasle H, Hovi L, et al. LongTerm Results in Children With AML: NOPHO-AML Study Group-Report of Three Consecutive Trials. Leukemia (2005) 19:2090-100. doi: 10.1038/ sj.leu. 2403962

41. Márky I, Björk O, Forestier E, Jónsson ÓG, Perkkiö M, Schmiegelow K, et al. Intensive Chemotherapy Without Radiotherapy Gives More Than 85\% EventFree Survival for Non-Hodgkin Lymphoma Without Central Nervous Involvement: A 6-Year Population-Based Study From the Nordic Society of Pediatric Hematology and Oncology. J Pediatr Hematol/ Oncol (2004) 26:55560. doi: 10.1097/01.mph.0000139772.98685.d2

42. Pui CH, Carroll WL, Meshinchi S, Arceci RJ. Biology, Risk Stratification, and Therapy of Pediatric Acute Leukemias: An Update. J Clin Oncol (2011) 29:551-65. doi: 10.1200/JCO.2010.30.7405

43. Gustafson G, Kreuger A, Clausen N, Garwicz S, Kristinsson J, Lie S, et al. Nordic Society of Paediatric Haematology and Oncology (NOPHO), Intensified Treatment of Acute Childhood Lymphoblastic Leukaemia has Improved Prognosis, Especially in Non-High-Risk Patients: The Nordic Experience of 2648 Patients Diagnosed Between 1981 and 1996. Nordic Society of Paediatric Haematology and Oncology (NOPHO). Acta Paediatrica (1998) 87:1151-61. doi: 10.1080/080352598750031149

44. Asdahl PH, Winther JF, Bonnesen TG, De Fine Licht S, Gudmundsdottir T, Anderson $\mathrm{H}$, et al. The Adult Life After Childhood Cancer in Scandinavia (ALiCCS) Study: Design and Characteristics. Pediatr Blood Cancer (2015) 62:2204-10. doi: 10.1002/pbc.25661

45. Pedersen CB. The Danish Civil Registration System. Scand J Public Health (2011) 39:22-5. doi: 10.1177/1403494810387965

46. Ludvigsson JF, Almqvist C, Bonamy AK, Ljung R, Michaelsson K, Neovius M, et al. Registers of the Swedish Total Population and Their Use in Medical Research. Eur J Epidemiol (2016) 31:125-36. doi: 10.1007/s10654-016-0117-y

47. Digital and Population Data Services Agency. Population Information System. Finland: Digital and Population Data Services Agency (2021). 
48. Pukkala E, Engholm G, Hojsgaard Schmidt LK, Storm H, Khan S, Lambe M, et al. Nordic Cancer Registries - An Overview of Their Procedures and Data Comparability. Acta Oncol (2018) 57:440-55. doi: 10.1080/0284186X. 2017.1407039

49. Lynge E, Sandegaard JL, Rebolj M. The Danish National Patient Register. Scand J Public Health (2011) 39:30-3. doi: 10.1177/1403494811401482

50. Mors O, Perto GP, Mortensen PB. The Danish Psychiatric Central Research Register. Scand J Public Health (2011) 39:54-7. doi: 10.1177/1403494810395825

51. Ludvigsson JF, Andersson E, Ekbom A, Feychting M, Kim J-L, Reuterwall C, et al. External Review and Validation of the Swedish National Inpatient Register. BMC Public Health (2011) 11:450. doi: 10.1186/1471-2458-11-450

52. Sund R. Quality of the Finnish Hospital Discharge Register: A Systematic Review. Scand J Public Health (2012) 40:505-15. doi: 10.1177/1403494812456637

53. Brooke HL, Talback M, Hornblad J, Johansson LA, Ludvigsson JF, Druid H, et al. The Swedish Cause of Death Register. Eur J Epidemiol (2017) 32:765-73. doi: 10.1007/s10654-017-0316-1

54. Bliddal M, Broe A, Pottegard A, Olsen J, Langhoff-Roos J. The Danish Medical Birth Register. Eur J Epidemiol (2018) 33:27-36. doi: 10.1007/s10654-018-0356-1

55. Cnattingius S, Ericson A, Gunnarskog J, Källen B. A Quality Study of a Medical Birth Registry. Scand J Soc Med (1990) 18:143-8. doi: 10.1177/ 140349489001800209

56. Gissler M, Louhiala P, Hemminki K. Nordic Medical Birth Registers in Epidemiological Research. Eur J Epidemiol (1997) 13:169-75. doi: 10.1023/ A:1007379029182

57. Thygesen LC, Daasnes C, Thaulow I, Bronnum-Hansen H. Introduction to Danish (Nationwide) Registers on Health and Social Issues: Structure, Access, Legislation, and Archiving. Scand J Public Health (2011) 39:12-6. doi: $10.1177 / 1403494811399956$

58. Jensen VM, Rasmussen AW. Danish Education Registers. Scand J Public Health (2011) 39:91-4. doi: 10.1177/1403494810394715

59. Baadsgaard M, Quitzau J. Danish Registers on Personal Income and Transfer Payments. Scand J Public Health (2011) 39:103-5. doi: 10.1177/ 1403494811405098

60. Statistics Sweden. Background Facts - Labour and Education Statistics 2016. Stockholm, Sweden (2019).

61. Statistics Sweden. Population and Housing Census 1960-1990 (TPR). Stockholm, Sweden (2000).

62. Ludvigsson JF, Svedberg P, Olen O, Bruze G, Neovius M. The Longitudinal Integrated Database for Health Insurance and Labour Market Studies (LISA) and Its Use in Medical Research. Eur J Epidemiol (2019) 34:423-37. doi: 10.1007/s10654-019-00511-8

63. Official Statistics of Finland (OSF). Population Structure [E-Publication]. Helsinki: Statistics Finland (2021).

64. Official Statistics of Finland (OSF). Educational Structure of Population [EPublication]. Helsinki: Statistics Finland (2021).

65. Ludvigsson JF, Otterblad-Olausson P, Pettersson BU, Ekbom A. The Swedish Personal Identity Number: Possibilities and Pitfalls in Healthcare and Medical Research. Eur J Epidemiol (2009) 24:659-67. doi: 10.1007/s10654-009-9350-y

66. Birch JM, Mardsen HB. Classification Scheme for Childhood Cancer. Int J Cancer (1987) 40:620-4. doi: 10.1002/ijc.2910400508

67. Steliarova-Foucher E, Stiller C, Lacour B, Kaatsch P. International Classification of Childhood Cancer, Third Edition. Cancer (2005) 103:1457-67. doi: 10.1002/cncr.20910

68. Kramarova E, Stiller CA. The International Classification of Childhood Cancer. Int J Cancer (1996) 68:759-65. doi: 10.1002/(SICI)1097-0215 (19961211)68:6<759::AID-IJC12>3.0.CO;2-W

69. Fritz A, Percy C, Jack A, Shanmugaratnam K, Sobin L, Parkin DM, et al. International Classification of Diseases for Oncology. 3rd ed. Geneva: World Health Organisation (2000).

Conflict of Interest: The authors declare that the research was conducted in the absence of any commercial or financial relationships that could be construed as a potential conflict of interest.

Publisher's Note: All claims expressed in this article are solely those of the authors and do not necessarily represent those of their affiliated organizations, or those of the publisher, the editors and the reviewers. Any product that may be evaluated in this article, or claim that may be made by its manufacturer, is not guaranteed or endorsed by the publisher.

Copyright (C) 2021 Erdmann, Frederiksen, Mogensen, Pedersen, Mader, Talbäck, Bautz, Hirvonen, Kyrönlahti, Korhonen, Hasle, Malila, Madanat-Harjuoja, Feychting and Winther. This is an open-access article distributed under the terms of the Creative Commons Attribution License (CC BY). The use, distribution or reproduction in other forums is permitted, provided the original author(s) and the copyright owner(s) are credited and that the original publication in this journal is cited, in accordance with accepted academic practice. No use, distribution or reproduction is permitted which does not comply with these terms. 